(This paper appeared as:

Verstraete, Jean-Christophe. 2004. The problem of subjective modality in the Functional Grammar model. In J. Lachlan Mackenzie and M. Gómez-González (eds.) A New Architecture for Functional Grammar (Functional Grammar series 24). Berlin: Mouton. 243-274.)

\title{
The problem of subjective modality in the Functional Grammar model
}

\author{
Jean-Christophe Verstraete
}

Fund for Scientific Research-Flanders \& University of Leuven

\section{Introduction $^{\mathrm{i}}$}

The purpose of this paper is twofold. I will first propose a number of modifications to the analysis of subjective modality in the Functional Grammar model (as developed in Hengeveld 1987, 1988, 1989, Dik 1997), using the English modal auxiliaries as a test case. I will then confront the alternative view of subjective modality resulting from these modifications with the architecture for FG proposed in Hengeveld (this volume). I will show how the proposed modifications can be dealt with more easily in the modular, top-down architecture than in the traditional FG model, but I will also argue that some further change is required in the model, more particularly concerning the optionality of layers at the representational level.

\subsection{The subjective-objective distinction}

The first part of this paper will be devoted to a critical examination of the distinction between subjective and objective modality in the traditional FG model. I will first propose a number of modifications to the criteria used to support the subjectiveobjective distinction. It is often argued that objective modality can be questioned and hypothesized, whereas subjective modality cannot. I will show that this is not entirely correct: conditionality and interrogation are not excluded for subjective modality, but interact with it in a special way. I will argue that this interaction can be explained as a consequence of the fundamentally interpersonal nature of subjective modality. 
On the basis of these modifications, I will then re-assess the position of deontic modality with respect to the subjective-objective distinction. In the FG model, as in many other frameworks, deontic modality is excluded from the subjective category. On the basis of the functions of deontic modals and their behaviour in reaction to the criteria of conditionality and interrogation, I will show that this exclusion is not justified, and that deontic modality can be subjective just like epistemic modality.

In the final section, I will argue that what sets deontic modals apart from their epistemic counterparts is not their potential for subjective status, but rather the type of domain over which they operate: subjective epistemic modality deals with the truth of propositions, whereas subjective deontic modality deals with the desirability of actions. This functional distinction is also grammatically reflected in the terms of the feature of tense: subjective epistemic modality operates over tensed SoAs, whereas subjective deontic modality operates over tenseless SoAs.

\subsection{Implications for the FG model(s)}

In the second part of this paper, I will confront this alternative analysis of subjective modality both with the traditional FG model in Hengeveld (1989) and Dik (1997) and with the alternative architecture for FG proposed by Hengeveld (this volume).

I will first argue that the exclusion of deontic modality from the subjective-modal category in the traditional FG model is a natural consequence of the understanding of layering that is implicit in the model. Given the assumption that the full set of layers is present in every main clause, the difference in domain between epistemic and deontic modality naturally leads to the exclusion of subjective deontic modality.

I will then show how the alternative analysis of subjective modality proposed in this paper can be accommodated more easily in the model proposed in Hengeveld (this volume). The modular separation between the interpersonal and the representational components allows for a subjective analysis of deontic modality in parallel with epistemic modality, independently from the fact that subjective epistemic and subjective deontic modality are associated with different types of domains. This difference in domain between epistemic and deontic modality, on the other hand, can be dealt with in terms of the top-down organization of the model, as an example of how choices within the interpersonal component have repercussions on choices within the representational component. 
To round off, I will also discuss one problem that is not dealt with in Hengeveld's (this volume) proposed model. In spite of the modular separation between the interpersonal and the representational components, the model still implicitly assumes that the full set of representational layers is relevant for every main clause. In order to adequately model subjective deontic modality, however, it is necessary to recognize optionality of layers in the representational component.

2. The analysis of modality in FG

I will first briefly outline the most important features of the analysis of modality in FG, as it has been developed in the work of Hengeveld (1987, 1988, 1989) and Dik (1997).

\subsection{Three categories}

The basis of the FG analysis of modality is a distinction between three different categories, which is itself based on a distinction between different functional layers in the clause with which the modal categories can be associated. More particularly, Hengeveld (1988, 1989) and Dik (1997) distinguish between the categories of

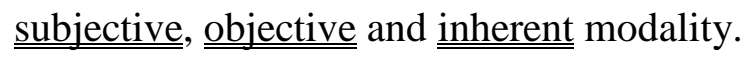

Inherent modality includes "all those linguistic means through which $\mathrm{S}$ can characterize the relation between a participant in a SoA and the potential actualization of that SoA" (Hengeveld 1988: 233). In terms of the traditional tripartition of epistemic, deontic, and dynamic modality (see, for instance, Palmer 1990), FG's inherent category includes the dynamic modals of ability and volition - the traditional participant-oriented modals - as well as those uses of deontic modality "in which it is reported that some participant in a state of affairs is under the obligation or has received permission to perform in that state of affairs" (Hengeveld 1988: 234). These types are exemplified respectively in examples (1), (2) and (3)

\section{Dynamic, ability}

(1) Well, certainly marriage has changed him. It mellowed him to the extent that he lost his drive and his motivation. In the midst of all that, he thought to himself, "Hey, wait a minute. I can still play this game." (CB) ${ }^{\mathrm{ii}}$ 


\section{Dynamic, volition}

(2) They were servicing AWACs planes for the Royal Saudi Air Force and completing contract work on a controversial air defense network for Saudi Arabia known as the Peace Shield. Boeing won't say how many of its employees are still there, but says those who stayed did so voluntarily. (CB)

\section{Deontic}

(3) But Ramadan means more than just physical deprivation. It has spiritual and moral obligations, too. Followers must refrain from bad thoughts, words and actions, perform special acts of charity and spend even more time than usual in worship. (CB)

Objective modality includes "all those linguistic means through which $\mathrm{S}$ can evaluate the actuality of a SoA in terms of his knowledge of possible SoAs" (Hengeveld 1988: 233). The relevant knowledge here can be either epistemic "knowledge of possible situations obtaining in S's conception of reality or of a hypothesized situation" (Hengeveld 1988: 234) or deontic "knowledge of possible situations relative to some system of moral, legal or social conventions" (Hengeveld 1988: 234). Accordingly, the objective category includes both epistemic and deontic modality, exemplified in (4) and (5)

\section{Epistemic}

(4) Is it possible that all human beings on earth today are descended from a single woman? (CB)

\section{Deontic}

(5) The bandages they wrapped around his face were loose enough to allow him to breathe, yet tight enough not to slip. You must not move a muscle," Ram Das warned him. That would cause a riot of terror. We're going to cover you with saffron dust to show we're carrying a corpse to the holy river. (CB)

Subjective modality, finally, involves "all those linguistic means through which S can express his commitment with regard to the truth of a proposition" (Hengeveld 1988: 233). This applies only to epistemic modality, exemplified in (6)

\section{Epistemic}


(6) Michael Jackson must have enjoyed his wedding in May, because he decided to have another one at his California ranch. (CB)

\subsection{Theoretical motivation}

Within the FG framework, the distinction between subjective, objective and inherent modality is theoretically motivated in terms of an association with different functional layers in the_structure of the clause (Hengeveld 1989, compare Foley \& Van Valin 1984, partly also Lyons 1977) ${ }^{\mathrm{iii}}$.

The starting point for the FG account of the different categories of modality is the distinction between a propositional and a predicational layer in the structure of the clause. According to Hengeveld (1989), this is grounded in the distinction between a representational and an interpersonal function in the clause (Halliday 1994), which take care respectively of the conceptualization of the situation referred to in the clause and the interactive intentions of the speaker towards the interlocutor. In this sense, the predicational and propositional layers represent two different functional perspectives on the traditional notion of State of Affairs (SoA): the predication is the representational perspective on the SoA, as a description of the situation to which the speaker refers in the clause, whereas the proposition is the interpersonal perspective on the SoA, as the propositional content for a particular communicative act performed by the speaker in the clause.

In terms of this distinction between interpersonal and representational functions of the SoA, a first distinction in the domain of modality is made between subjective modality on the one hand and objective and inherent modality on the other hand. Subjective modality serves to express the speaker's commitment, and is therefore an interpersonal category, taking care of the speaker's interactive positioning with respect to the SoA as the object of his speech act. In the FG model, this is accommodated theoretically by analysing subjective modality as an operator of the propositional layer. Objective and inherent modality, on the other hand, do not have any interpersonal function, and are therefore associated with the predicational layer.

Within the non-interpersonal domain, a further distinction is made between objective and inherent modality on the basis of their divergent position with respect to the SoA. Inherent modals serve to evaluate the actualization of the SoA from a perspective internal to the SoA, more particularly by indicating a particular type of 
relation (for instance ability or willingness) between one of the participants and the SoA, whereas objective modals evaluate it from an external perspective. In the FG model, this is accommodated theoretically in terms of different positions with respect to the predicational layer: the SoA-external function of objective modals is reflected in their position as operators with scope over the predication, whereas the SoAinternal function of inherent modals is reflected in their position as categories internal to the predication.

\subsection{Criteria}

Hengeveld (1988) argues that the functional distinction between subjective and objective modality is also reflected in their grammatical behaviour, and adduces a number of grammatical criteria to which subjective and objective types of modality react differently. In addition to tense, polarity and pragmatic appropriateness of questioning the source of information, which will not be dealt with in this paper, Hengeveld also mentions conditionality and interrogation: "Objectively modalized predications can be questioned, subjectively modalized ones cannot"; "Objectively modalized predications can be hypothesized in a conditional sentence, subjectively modalized ones cannot" (Hengeveld 1988: 236).

\subsection{Summary}

\section{Table 1 about here}

\section{Criteria: refinement and explanation}

In order to demonstrate the need for an alternative analysis of the subjective-objective distinction, I will first show that the criteria used to distinguish between subjective and objective modality, especially conditionality and interrogation, are not entirely accurate as they are formulated in Hengeveld (1988). Subjective modals are not excluded from conditional and interrogative constructions: rather, using subjective modals in these constructions leads to modifications in their interpretation that do not occur with objective modals. 
These descriptive refinements do not imply a rejection of conditionality and interrogation as criteria for the subjective-objective distinction. The semantic modifications observed for subjective modals in these constructions provide an important key to their fundamentally interpersonal status: the semantic effects of interrogation and conditionality can be explained in terms of the interpersonal function of subjective modality described in Hengeveld (1988: 233), viz. the fact that they serve to encode positions of commitment with respect to the SoA described in the utterance.

\subsection{Conditionality}

Hengeveld (1988: 236) proposes to use conditionality as an absolute criterion for the subjective-objective distinction, and argues that objective modality can occur in the protasis of conditional constructions, whereas subjective modality cannot.

This absolute interpretation of the conditionality criterion may work for the distinction between modal adjectives and adverbs ${ }^{\text {iv }}$, but it is not an adequate account of the behaviour of modal auxiliaries in conditional contexts: subjective modals $\underline{\underline{\mathrm{can}}}$ occur in conditionals, but their interpretation is affected by the conditional context. Subjective modals in the protasis of conditional constructions invariably become echoic (see also Palmer 1990: 182): they do not express the current speaker's opinion, but echo an opinion that has been voiced in or is implied by the preceding discourse. For instance,

(7) In distilling a statement of theme from a rich and complicated story, we have, of course, no more encompassed the whole story than a paleontologist taking a plaster mold of a petrified footprint has captured a living brontosaurus. A writer (other than a fabulist) does not usually set out with theme in hand, determined to make every detail in the story work to demonstrate it. Well then, the skeptical reader may ask, if only some stories have themes, if those themes may be hard to sum up, and if readers will probably disagree in their summations, why bother to state themes? (CB)

In (7), the epistemic position expressed by may is crucially not the position of the 'skeptical reader' who uses the conditional construction, but an opinion voiced by 
some other speaker which the 'skeptical reader' echoes in his conditional construction without committing himself to it. Thus, subjective modals are not excluded in conditional contexts, but their interpretation is affected by the conditional.

This semantic effect does not occur with non-subjective modals like the modal of ability in (8): the interpretation of can't in the conditional in (8) is not different from its interpretation in non-conditional contexts.

(8) Phillips: Oh, I think it's just the--the same thing as the sign that they had during the campaign, that everything else was secondary to the economy. If Bill Clinton can't deal with the economy in the next year or year and a half, he's really going to be in trouble in--in the whole breadth of his administration. (CB)

\subsection{Interrogation}

Hengeveld (1988) argues that objective modality can be questioned, whereas subjective modality cannot. Again, I agree that this may be the case when subjective and objective modality are realized as modal adverbs and adjectives respectively ${ }^{\mathrm{v}}$, but it is certainly not the case for modal auxiliaries. Subjective modal auxiliaries can occur in interrogatives just like objective ones, as shown in examples (9) and (10):

(9) THOMPSON: If the trials are successful, might this be used as the first line of treatment of cancer? THORPE: Well that's exactly where we are going. We are hoping that this will replace conventional chemotherapy. (CB)

(10) I mean maybe we've got no choice if we want to do it but I mean erm do you think it's possible to do anything worthwhile in history lessons or can this work really only take place in somewhere like civics social studies sociology politics? (CB)

As with conditionality, the difference between subjective and objective modals is not a matter of acceptability in interrogative contexts, but of the way the interpretation of the modal is affected by the interrogative construction. With subjective modality, the commitment the position encoded by the modal undergoes a shift of orientation under the influence of interrogation. In declarative contexts, the responsibility for the 
position is assigned to the speaker, but in interrogative contexts like (9) or (10), the responsibility for the position encoded by subjective modals like epistemic might and can is no longer taken by the speaker, but is assigned to the interlocutor in the next turn: "are you committed to this position?" rather than "I am committed to this position".

For non-subjective modals, on the other hand, interrogation does not affect the interpretation of the modal. Since the interpretation of non-subjective modality does not require any assignment of responsibility, it does not undergo any shift of orientation under the influence of interrogation. For instance, if we look at examples like (11) or (12):

(11) They've already worried the charts and won many admirers with the single Fun for Me. Can they do it live? It's time to find out. (CB)

(12) First-time buyers should ask: Who is responsible for a title search and abstract? Who will provide title insurance? Must the termite inspection be paid before closing (in which case you will need a receipt), or can it be paid at settlement? (CB)

Unlike with the subjective modals in (9) and (10), the non-subjective uses of can and must in (11) and (12) do not undergo any shift of orientation in interrogative contexts. They do not imply any responsibility for a position of commitment, and therefore they are not affected by interrogation. Rather than taking part in the speakerinterlocutor transfer of responsibility, dynamic can and deontic must in (11) and (12) belong to the content with respect to which positions of responsibility are taken or transferred. With must in (12), for instance, the obligation or necessity denoted by must is part of the content about which speaker and interlocutor negotiate epistemically ("do you think it is obliged or necessary to pay the termite inspection before closing?"; see further in section 5.2.). The same goes for can in (11): the ability denoted by the modal is part of the content that is subject to epistemic negotiation ("do you think they are able to do the same thing live?").

\subsection{Explanation of the behavioural distinctions}


The descriptive modifications proposed in the previous two sections do not invalidate the basic idea that conditionality and interrogation can be used as criteria for the subjective-objective distinction. The behaviour of subjective and objective modality in reaction to conditionality and interrogation $\underline{\underline{i s}}$ different, only not in terms of unacceptability but in terms of the effect on the interpretation of the modal. In this section, I will show how these semantic effects do not merely serve as criteria to differentiate between subjective and objective uses of modal auxiliaries, but that the difference in behaviour can actually be linked back to the functional basis of the subjective-objective distinction proposed in Hengeveld (1989). The effects of echointerpretation for conditionals and shift of orientation for interrogatives can be explained as a consequence of the fact that subjective modals take part in the interpersonal organization of the clause: they serve to encode positions of commitment with respect to the SoA described in the utterance.

The fact that subjective modality becomes echoic in the protasis of conditional constructions is a consequence of the clash between the function of the subjective modal, which is to encode a position of commitment by the speaker, and the function of the conditional marker, which is to suspend the speaker's commitment with respect to the proposition in its scope. Conditionals are special contexts in that they operate with suppositions rather than assertions (Declerck \& Reed forthcoming): the typical function $^{\mathrm{vi}}$ of the conditional marker if is to suspend the commitment of the speaker with respect to the proposition in its scope (Dancygier 1998) and thus to treat it as a mere supposition in the context of the apodosis. For objective modals, this suspension of commitment is unproblematic, because objective modality does not encode any type of speaker-commitment. For subjective modals, however, the suspension of speaker-commitment in conditionals clashes with the very function of subjective modality, which is to encode the speaker's commitment with respect to the proposition. This clash leads to an echoic reinterpretation, which could be regarded as the interpretational compromise between the two conflicting functions in the modal and the conditional: the position encoded by the modal is no longer a position of the current speaker, because the conditional context suspends such positioning, but resumes a position taken in the preceding discourse, usually by another speaker. That is the only way a modal can still encode a position in a context which does not allow such positioning by the current speaker. 
The fact that subjective modality undergoes a shift in orientation in an interrogative context is again a consequence of its position-encoding function. A position of commitment necessarily implies responsibility for that position, and that is what the declarative-interrogative contrast operates on. The declarative allows the speaker to take the responsibility for the position encoded in the subjective modal in his own turn, whereas the interrogative allows the speaker to transfer this responsibility to the interlocutor in the next turn (Davies 1979). Unlike subjective modals, objective modals do not serve to encode any positions of commitment, and therefore do not undergo any shift of orientation under the influence of interrogation. Interrogation can only interact with modality if the function of the modal implies assignment of responsibility in discourse.

\section{The position of deontic modality}

On the basis of the modified criteria, the position of deontic modality in the overall model for modality in FG can now be reconsidered. In Hengeveld (1988), deontic modality is included in the objective and inherent categories, but crucially not in the subjective category. FG is not the only framework to treat deontic modality differently from epistemic modality: deontic modality has often been set apart in the analysis of the subjective-objective distinction. Foley \& Van Valin (1984), for instance, do not recognize any subjective-objective ambiguity for deontic modality at all, and treat the deontic modals as 'core' operators (more or less the equivalent of FG's predicational operators) together with the dynamic modals. Even Lyons (1977), who seems to recognize both subjective and objective types for deontic modality, still differentiates his analysis of subjectivity by associating subjectivity with different functional layers (in terms of Hare's (1970) tropic-neustic-phrastic framework) depending on the epistemic or deontic nature of the modal. Halliday (1970) is in fact the only one who recognizes a subjective function for deontic modality that is fully parallel with the subjective function of epistemic modality. In this section, I will try to defend this position both on the basis of the function of deontic modals (section 4.1.) and on the basis of their behaviour in reaction to some of the criteria for subjectivity (section 4.2.). In the next section, I will show that the difference between epistemic and deontic modality does not lie in their potential for subjective status, but in the domain over which they operate. 
4.1. The functions of deontic modals: inherent, objective and subjective

\subsubsection{Types of deontic modality}

In terms of function, there are at least three types of deontic modality that can be distinguished in English, illustrated in (13)-(16) below:

(13) "I need to see Izzy," I said. "I told you, she's sound asleep. Deeply asleep." "May I see for myself?" You may not, you shit-sucking liar! You cheat. You coward. You sit!" I pulled back the heavy dining room chair and sat before the typewriter. (CB)

(14) What we want is for the right honourable gentleman to use the full weight of his office. We are getting tired of a cosmetic approach an oversanguine approach. There is a crisis and he must act now <ICE-GB:S1B-056 \#8789:1:F>

(15) But Ramadan means more than just physical deprivation. It has spiritual and moral obligations, too. Followers must refrain from bad thoughts, words and actions, perform special acts of charity and spend even more time than usual in worship. (CB)

(16) But to reach orbit an object must accelerate to a speed of about 17,500 miles per hour (28,000 kilometres per hour, called satellite speed or orbital velocity) in a horizontal direction; and it must reach an altitude of more than 100 miles (160 kilometres), in order to be clear of the atmosphere. $<$ ICE-GB:W2B-035 \#39:1>

In examples (13) and (14), the function of the deontic modal is to express the speaker's commitment to the permission or obligation encoded in the modal: may and must in these examples can be paraphrased as "I do not allow you to ..." and "I oblige him to ...". An example like (15), on the other hand, does not express the speaker's commitment to the obligation signalled by the modal ("I want the followers to ..."), but rather reports on the existence of a particular obligation without necessarily committing the speaker to it. Unlike in (13) and (14), the speaker is not the deontic source of the obligation or permission, but merely the one who describes the existence 
of such an obligation, which may itself originate from another source. An example like (16), finally, is different from both (13) and (14) and from (15) in that no deontic source is involved at all. Must in (16) does not express an obligation originating from a deontic source (irrespective of the question whether this source is identical with the speaker or not), but denotes a necessity that is inherent in the situation ${ }^{\text {vii: }}$ the state of things is such that if the object in question is to reach orbit, a speed of $17,500 \mathrm{mph}$ is required.

The FG analysis of modality also recognizes functional ambiguity for deontic modals, and accounts for it in terms of the distinction between objective and inherent modality. Examples like (13) and (14) would be classified as objective, i.e. expressing an evaluation of the actuality of the SoA on the basis of the speaker's "knowledge of possible situations relative to some system of moral, legal or social conventions" (Hengeveld 1988: 234). Examples like (15), on the other hand, would be classified as inherent, i.e. "report[ing] that some participant in a state of affairs is under the obligation or has received permission to perform in that state of affairs" (Hengeveld 1988: 234).

\subsubsection{An alternative to the FG categorization of the types}

I do not believe that the objective-inherent dichotomy is an adequate way to account for the functional distinction between (13) and (14) on the one hand and (15) on the other hand. In this section, I will argue that in terms of function it is more plausible to analyse (13) and (14) as subjective in parallel with epistemic modality rather than as objective. Examples like (15), on the other hand, should be analysed as the objective counterparts of such subjective uses rather than grouping them together with the dynamic modals of ability and volition in the inherent category. Examples like (16), finally, which are not explicitly dealt with in the FG framework ${ }^{\text {viii }}$, are the most plausible 'deontic' candidates for the inherent category, because of their functional similarity with the dynamic modals of ability and volition.

The FG analysis of examples like (13) and (14) as representatives of the objective category implies that the function of the modal here is to provide an evaluation of the actuality of the SoA in terms of the speaker's knowledge of conventions or morals. I do not think that this is an adequate description of the function of may and must in (13) and (14), as also argued by Goossens (1996: 49-50): in these examples, the 
speaker does not evaluate the actuality of the SoA, but expresses his commitment to the permission or obligation. It is the speaker who wants the SoA to be actualized: the speaker is not evaluating descriptively but acting interpersonally. Functionally, therefore, this use comes closer to the category of subjective modality, which "expresses [the speaker's] commitment" (Hengeveld 1988: 233). Given the function of examples like (13) and (14), I see no reason to exclude deontic modality form the subjective category: deontic modals can be subjective just like epistemic ones, the only difference is that the commitment in question does not concern the truth of propositions, but the desirability of actions (see further in section 5).

For examples like (15), the functional characterization proposed by FG is entirely adequate. Examples like these do not involve the speaker's commitment to the obligation: the speaker is the one who reports on the existence of an obligation for some participant to act but does not coincide with the deontic source of this obligation. In spite of the adequacy of the functional characterization for such examples, however, I do not think that they should be grouped together with dynamic modals of ability and volition as members of the inherent category, as is the case in the FG analysis. There are two important arguments for distinguishing examples like (15) from the modals of ability and volition. On the one hand, the obligation expressed by must in (15) still implies some external source, whereas the dynamic modals of ability and volition never involve any external source but are entirely internal to the SoA. In this sense, (15) naturally groups together with (13) and (14) in contrast with the dynamic modals of ability and volition: (13), (14) and (15) always imply some external source (which may or may not coincide with the speaker), whereas the dynamic modals of ability and volition do not involve any source at all. The second reason for keeping must in (15) apart from the dynamic modals of ability and volition is that within the deontic system there is a another use of must which $\underline{\underline{\text { does }}}$ naturally group together with the modals of ability and volition in that it does not involve any external source. Must in (16) is similar to the dynamic modals and different from (13), (14) and (15) because it is not related to any deontic source: must in (16) does not express an obligation coming from an external source but simply expresses the existence of a necessity internal to the SoA.

I believe that we can do justice to both these arguments by redistributing examples like (15) and (16) over the objective and inherent categories: (15) should be regarded as objective rather than as inherent, and (16) should be included in the inherent 
category. Including examples like (15) in the objective category does justice to its natural affinity with subjective modality: in both cases, the modal is related to a deontic source, and the difference between the two relates to the question whether the deontic source coincides with the speaker (subjective) or not (objective). On the other hand, the 'gap' that is left by taking examples like (15) out of the inherent category is more adequately filled by examples like (16): grouping these examples together with the dynamic modals of ability and volition does justice to their shared SoA-internal function ${ }^{\text {ix }}$.

Thus, a consideration of the various functions of deontic modality leads to the following alternative proposal for the subjective-objective-inherent matrix:

\section{Table 2 about here}

\subsection{Criteria applied to deontic modality}

A subjective analysis for deontic modals like (13) and (14) in parallel with epistemic modality is further justified by their behaviour in reaction to the various criteria that can be used to distinguish between subjective and objective modality. Subjective deontic modals are just as much speaker-hearer related as their subjective epistemic counterparts, and therefore show the same behaviour with respect to conditionality and interrogation.

\subsubsection{Conditionality}

As already argued in section 3.1, subjective epistemic modality becomes echoic in conditional constructions: it does not express a position taken by the speaker who uses the conditional, but echoes one voiced by another speaker in the preceding discourse context. With subjective deontic modality, conditionality can have the same effect although because of the almost systematic ambiguity with non-subjective functions it is not automatic the way it is for epistemic modals. For instance, if we compare (17) with (18):

(17) The key stumbling block remained Republican insistence on a Medicare premium increase. Mr Clinton argued that Medicare increases were not 
necessary to meet demands for a balanced Budget. If America must close down access to quality education, a clean environment and affordable health care for our seniors in order to keep the government open, then that price is too high," Mr Clinton said in vetoing the temporary spending Bill. (CB)

(18) I suffer from acne but also burn very easily - can I use sun oils? It is always best to tan gradually, but especially so if you have a sensitive skin. If you must be exposed to sun that may burn you, it may be wise to use a sun-screen preparation. (CB)

In (18), the non-subjective deontic modal is unproblematic in the conditional: it does not echo any position taken by another speaker, but simply expresses that if a situation occurs that requires exposure to sun, it is wise to use sun-screen preparation. In (17), on the other hand, the subjective deontic modal is echoic: must in the protasis does not simply express the existence of necessity or obligation, but echoes another speaker's commitment to such an obligation. This is evident from the fact that the conditional in (17) is rhetorically directed against those who are committed to Medicare premium increases. The speaker in (17) takes up the Republicans' position in his conditional protasis without committing himself to it: the must in (17) is clearly a must that is attributed to the Republicans, and not a position to which Clinton himself subscribes.

\subsubsection{Interrogation}

In section 3.2., it has already been argued that interrogation interacts with subjective modality, in that the responsibility for the position encoded by the modal is transferred to the interlocutor's next turn in an interrogative context. The same applies to subjective deontic modality, as illustrated in the following examples:

(19) Dr Gwyn Adshead thank you very much for joining us. And please may I call you Gwyn? Certainly. Thank you. That's a good start. What are the differences generally speaking between a counsellor a therapist and a psychiatrist? (CB)

(20) You've got to be there by nine o'clock in the morning at the latest. You'll be crossing the main refugee routes. Shouldn't be too bad." Must I leave my platoon, sir? At this moment?" Stop arguing and get down there. It's nobody's 
fault but yours that you speak fluent German. You know perfectly well every linguist's name is listed." (CB)

Both in (19) and in (20), the deontic modals express some position of commitment to the permission and the obligation to carry out the action in question, but the responsibility for this commitment is not the speaker's. Rather, the speaker transfers this responsibility to the interlocutor's next turn, i.e. asks whether the interlocutor is committed to it: "do you allow me to call you Gwyn?" and "do you oblige me to leave my platoon?". For non-subjective deontic modality, on the other hand, the modals do not take part in the speaker-interlocutor exchange: if a modal does not express any position of commitment, there is no responsibility to be assigned. An example like (21) below cannot be paraphrased as "do you want the money to be repaid to A?" like (19) or (20), but should rather be interpreted as "do you think it is obliged/necessary to repay the money?". What is exchanged between speaker and interlocutor in this example is not a position of deontic commitment, but rather a position of epistemic commitment to the existence of necessity or obligation (see further in section 5.2.).

(21) [From a letter asking advice about legal matters] Can I use a portion of the proceeds from the first sale effect improvements to the second property? If so,

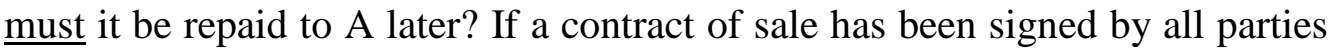
and my aunt was to die, will that contract still be binding? (CB)

\subsection{Conclusion}

If we look at the function of deontic modals in examples like (13) or (14), and their behaviour in conditionals and interrogative contexts, there is no reason to exclude deontic modality from the subjective category. Deontic modals can be subjective just like epistemic modals, the only difference is the domain of the modality. Whereas epistemic modals express positions concerning the truth of propositions, deontic modals express positions concerning the desirability of actions. Within the traditional FG conception of layering, it is probably this distinction of domains that has been the motivation for the exclusion of deontic modality from the subjective category, as I will argue in section 6 . 
5. Subjective deontic versus subjective epistemic modality: different domains

As I tried to show in the previous section, deontic modality can be subjective just like epistemic modality, both in terms of the function of encoding positions of commitment, and in terms of the behaviour in reaction to the different criteria for subjectivity. In this section, I will argue that the difference between the two categories lies in the domain over which they operate rather than in their subjective status. Subjective epistemic modality encodes positions of commitment to the truth of propositions, whereas subjective deontic modality encodes positions of commitment to the desirability of actions. I will show that this functional difference is also reflected in the grammatical behaviour of the categories, more particularly in terms of the category of tense: subjective epistemic modality operates over tensed domains, whereas subjective deontic modality operates over tenseless domains.

\subsection{Tensed versus tenseless domains}

The distinction between tensed and tenseless domains has traditionally been associated with the distinction between the basic mood types of indicative and imperative (Bolinger 1968 \& 1977, Lyons 1977: 746-747, Bolkestein 1980: 41).

(22) John is aware of the problems.

(23) Give me the money!

In indicative clauses like (22), the SoA represented is always located with respect to the temporal zero-point (the time of encoding and/or decoding by speaker and/or hearer, Declerck 1991b): the category of tense locates the actualization of the SoA in the past, present or future relative to the temporal zero-point. In imperative clauses like (23), on the other hand, there is no tense marking and the SoA is consequently not located with respect to the temporal zero-point. It might be objected that imperatives are not tenseless but have an inherently future orientation, but this 'future' orientation cannot be considered a tense the way future tense is in the indicative mood. Future tense establishes a relation to the speaker's here-and-now by locating the actualization of an SoA at a point in time which is later than the time of utterance, but the so-called 'future' orientation in imperatives cannot reasonably be said to locate the actualization 
of the SoA at a particular point in time later than the moment of utterance. As an object of the speaker's desire or will, the SoA in an imperative is not 'located' but rather a purely 'virtual' concept (Bolinger 1968 \& 1977). Virtuality is very different from location in the future: location in the future still entails some relation with the world of the speaker's here-and-now, which can be evaluated in terms of truth and falsity, whereas virtuality implies no relation at all with the world of the here-and-now and is therefore outside the realm of truth and falsity.

The same contrast between tensed and tenseless domains that distinguishes indicative from imperative mood also distinguishes subjective epistemic modality from subjective deontic modality. This becomes especially clear if we look at the present-perfect contrast for the main verb following the subjective modal auxiliary, which has a different functional value depending on the epistemic or deontic nature of the modal. For instance, if we compare (24) with (25):

(24) John must surely be aware of the problems.

John must surely have been aware of the problems.

(25) Jack must give me the money, or I'll kill him.

Jack must have given me the money (by ten), or I'll kill him.

In subjective-epistemic (24), the function of the contrast between present and perfect main verb is to locate the actualization of the SoA differently with respect to the temporal zero-point: perfect locates it in the past relative to the zero-point, whereas present locates it in the non-past. Thus, subjective epistemic modality operates over a tensed domain, and is therefore paradigmatically equivalent to the bare indicative mood. In subjective-deontic (25), on the other hand, the contrast between present and perfect does not serve to locate the actualization of the SoA differently relative to the temporal zero-point. Both with present and with perfect main verb, the SoA is a desired and therefore still virtual SoA just like in imperative clauses: the perfect in this case does not locate in the past, but simply indicates that actualization of the virtual SoA denoted by the predication is desired by a specific point in time (here lexically realized in by ten). Thus, subjective deontic modality operates over tenseless domains and is therefore paradigmatically equivalent to the imperative mood: its SoA is not located in time with respect to the temporal zeropoint, but is simply an unlocalized, virtual SoA. 


\subsection{Subjective versus non-subjective deontic modality}

The paradigmatic equivalence between the imperative mood and subjective deontic modality has sometimes been challenged on the basis of the fact that deontic modals can have features which are normally excluded for imperatives, like tense marking and propositional attitude markers (Bolkestein 1980: 36-47). In this section, I will show that these arguments apply only to nonsubjective (objective or inherent) uses of deontic modality, but crucially not to subjective uses. More particularly, I will argue that what is interpersonally at issue in structures with nonsubjective deontic modals is the subjective epistemic modalization realized in the indicative mood: this is what explains the presence of typically epistemic features such as tense and propositional attitude marking in such structures.

(26) You must ask him if he fancies me and love him and ask him why he says he'd phone me that often, ask him that, you must say, right yeah but don't tell him that I told you to ask him, yeah (CB)

(27) The 16-strong Scottish squad is free to travel south and whoop it up. Johnston's ex-Rangers pals - six are named in the party - are likely to take advantage, but the proviso is they must be back at Motherwell by $2.30 \mathrm{pm}$ on Sunday to work off their excesses.

The deontic modal must in (26) above is subjective: it serves to encode the speaker's commitment to the desirability of the action in question, and the SoA with respect to which the speaker expresses this commitment is not located relative to the temporal zero-point but still 'virtual'. This subjective use of deontic modality can unproblematically be regarded as a paradigmatic equivalent of the imperative, which equally expresses the speaker's commitment to the desirability of the action and equally operates on tenseless SoAs. In this sense, it is not a coincidence that subjective deontic must in (26) naturally alternates with imperative structures in one and the same stretch of discourse.

The deontic modal must in (27) is objective: it does not express the speaker's commitment to the desirability of the action, but merely reports on the existence of an obligation originating from another deontic source. Structures with this type of 
deontic modality behave very differently from structures with subjective deontic modality.

(28) The Scottish squad had to be / will have to be back at Motherwell by $2.30 \mathrm{pm}$ on Sunday to work off their excesses.

(29) Fortunately, the Scottish squad must be back at Motherwell by $2.30 \mathrm{pm}$ on Sunday to work off their excesses.

(30) Must the Scottish squad be back at Motherwell by $2.30 \mathrm{pm}$ on Sunday?

First of all, they are not tenseless but tensed: the issue in these structures is no longer the speaker's commitment to the obligation, but rather the existence of the obligation in question. This existence can be located in the past, present or future just like any other SoA, as shown in (28). Secondly, structures like (27) also allow the expression of propositional attitude markers like probably, possibly, fortunately or sadly_(Bolkestein 1980: 40-42), as shown in (29). Again, the object with respect to which the attitude is expressed is the existence of the obligation rather than any speaker's commitment to such obligation. Finally, objective deontic modality behaves differently from its subjective counterpart in reaction to interrogation. The responsibility transferred to the interlocutor's next turn in (30) is not deontic ("do you want the players to ...?") as would be the case for subjective deontic uses like (26) but epistemic ("is it the case that the players are obliged to ...?").

What these features show is that structures with objective deontic modality are subjectively modalized in epistemic terms, by the indicative mood. What is interpersonally at issue in these structures is not deontic commitment to desirability of actions but rather epistemic commitment encoded by the indicative mood: the speaker's or interlocutor's commitment to the truth of a proposition about the existence of an obligation ("is it or is it not the case that this obligation exists?"). The presence of subjective epistemic modalization in such structures can explain the availability of tense: as shown in the previous section, subjective epistemic modality operates on tensed SoAs. The availability of propositional attitude markers is also a typically epistemic feature: propositional attitudes can only be expressed in epistemic utterances, where the truth of a proposition is at stake, but not in subjective deontic utterances where the desirability of an action is at stake (Verstraete 2000, see also Moutaouakil 1996: 212-213). The behaviour of interrogation, finally, can also be 
linked up with the subjective epistemic modalization encoded in the indicative. What the interrogative transfers to the interlocutor in (30) is the responsibility for an epistemic rather than a deontic position, typically paraphrased with an epistemic predicate ("do you think it is the case that the players are obliged to ...?" rather than “do you want the players to ...?”).

In this sense, the objections raised in the literature against the paradigmatic equivalence between deontic modality and the imperative mood are valid only for nonsubjective deontic modality: structures with nonsubjective deontic modals are epistemically modalized by the indicative mood, and can therefore not be regarded as paradigmatically equivalent to imperatives. But this argument crucially applies only to nonsubjective deontic modality. Subjective deontic modality does not show any of these features: it does operate on tenseless SoAs, does not allow expression of propositional attitude markers ${ }^{\mathrm{x}}$ and the speaker-interlocutor transfer effected by the interrogative is deontic rather than epistemic. In this sense, the arguments against paradigmatic equivalence with the imperative cannot be used for the deontic category as a whole, but should also take into account the functional diversity within the deontic category.

\subsection{Summary model}

Table 3 below summarizes the most important differences between the traditional FG treatment of modality and the alternative proposal put forward in this paper.

\section{$\underline{\text { Table } 3 \text { about here }}$}

The central point of divergence between the two proposals is the possibility of subjective status for deontic modality, but this also has repercussions for the overall organization of the model. At the level of speaker-hearer interaction, this implies that there is a functional dichotomy between utterances where speaker and interlocutor negotiate about the desirability of actions, and those where speaker and interlocutor negotiate about the truth of propositions. This bifurcation is also continued at the representational level, in the sense that the material negotiated in the interaction is different depending on the subjective-deontic or subjective-epistemic nature of the negotiation. The relevant parameter here is the category of tense, with its function of 
locating the SoA with respect to the speaker's temporal zero-point: subjective-deontic modality operates on bare SoAs, which are not located with respect to the temporal zero-point, whereas subjective-epistemic modality operates on tensed SoAs, because location with respect to the temporal zero-point is a necessary prerequisite for arguing about truth or falsity (see Halliday 1994: 75).

\section{Implications for the FG model(s)}

In the final section of this paper, I will confront my analysis of subjective modality both with the traditional layered model of the clause as it is presented in Hengeveld (1989) and Dik (1997), and with the alternative model proposed in Hengeveld (this volume). I will argue that the exclusion of deontic modality from the subjective-modal category (Hengeveld 1988, 1989) is a natural consequence of the way the theory of layering has been formulated so far: given the assumption that the full set of layers is present in every (main) clause, the difference in domain between epistemic and deontic modality naturally excludes the possibility of subjective deontic modality. I will also show, however, that the modular top-down organization proposed in Hengeveld (this volume) is better suited to deal with subjective deontic modality. On the one hand, the modular separation between interpersonal and representational components allows one to dissociate the question of subjective status of epistemic and deontic modality from the question of the type of domain over which the modals operate: the domains of the modal operators are a representational issue, whereas the subjective status of the operator is an interpersonal issue that can be dealt with in its own right. On the other hand, the connection between the interpersonal distinction [subjective epistemic - subjective deontic] and the representational distinction [tensed SoAs - tenseless SoAs] can still be incorporated in the model as an example of topdown organization, where representational distinctions are steered from the interpersonal component.

\subsection{Theory-internal problems with subjective-deontic modality}

The exclusion of deontic modality from the subjective category in earlier FG proposals can probably be attributed to the understanding of layering that is implicit in the model presented in Hengeveld (1989) and Dik (1997). Given the difference in 
domain between epistemic (truth of propositions) and deontic modality (desirability of actions), it is a logical step within the traditional FG version of layering to exclude deontic modality from the subjective category, as I will try to show in this section.

The basic difference between subjective epistemic modality and (what I claim to be) subjective deontic modality is a difference in domain. As shown in the previous section, subjective epistemic modality expresses commitment to the truth of propositions, whereas subjective-deontic modality expresses commitment to the desirability of actions. In grammatical terms, this difference in domain is reflected in the presence versus absence of tense in the non-modalized part of the utterance: subjective epistemic modality operates over tensed SoAs, located with respect to the speaker's temporal zero-point, whereas subjective deontic modality operates over tenseless, virtual SoAs. This is a descriptively relevant distinction that will probably be recognized in most analyses, but the question is how to incorporate it in the model. The decision within FG to locate the 'highest' types of epistemic and deontic modality at different sides of the tense operator can be regarded as one way to do justice to the distinction in domains - epistemic modality at the proposition level, with scope over the tense operator, and deontic modality at the predication level, without scope over the tense operator.

I fully agree that the distinction between subjective epistemic and deontic modality in terms of tense should somehow be included in the model, but the question is whether association of the modals with different layers is the right way to do this. In the FG conception of layering, association with different layers necessarily also implies different status for operators, and this makes it impossible to analyse both epistemic and deontic modality as subjective. If the highest type of deontic modality is associated with the predication, and the highest type of epistemic modality is associated with the proposition, it is impossible to do justice to the functional and behavioural similarities between the two categories that point towards a shared subjective status. The reason is that the full set of layers is considered to be relevant for every type of (main) clause, more or less in the form of a template: in this sense, utterances with subjective deontic modality as an operator over the predicational layer still have to contain a propositional layer with an associated slot for the subjective epistemic operator ${ }^{\mathrm{xi}}$ and therefore the deontic modal cannot be analysed as subjective in the same way as epistemic modals. 
Thus, the assumption that every main clause contains a propositional layer is the most important obstacle to the inclusion of subjective deontic modality in the model. The presence of a propositional layer need not be regarded as a universal characteristic of clauses, however: this idea probably derives from the assumption implicit in many frameworks that every utterance is fundamentally about knowledge. Following Halliday (1975, 1994) and McGregor (1997), I believe that the subjectivedeontic domain of action and the subjective-epistemic domain of knowledge constitute a fundamental dichotomy in the system, such that in terms of subjective modalization any utterance belongs either to the deontic domain or to the epistemic domain, i.e. that any utterance argues either about action or about knowledge. This also implies that only epistemic utterances contain a propositional layer. Subjective deontic structures lack all propositional characteristics (McGregor 1997: 216-217), both functionally (they argue about virtual action) and grammatically (they are tenseless): what subjective deontic modality operates on is not propositions but 'unlocalized' SoAs, tenseless 'virtual' SoAs which are considered by the speaker in terms of desirability.

Thus, one alternative to the traditional FG analysis is to give up the implicit assumption that every main clause structure has a propositional layer ${ }^{\mathrm{xii}}$. This way the distinction in tense between subjective epistemic and subjective deontic modality can be incorporated in the model (in terms of the presence and absence of a propositional layer in the structure of the clause) in a way that does not a priori exclude the parallel analysis of the two modal categories as subjective. As I will show in the following section, however, implementing this alternative proposal requires two types of modification in the traditional formulation of the FG model: a modular separation between the interpersonal and the representational structures of the clause, and optionality of layering in the representational structure.

\subsection{The usefulness of modularity and top-down organization}

The two most important features in Hengeveld's (this volume) alternative architecture for the FG model are modularity and top-down orientation. Modularity means that the continuous layering from terms to illocutionary frames of the traditional model is abandoned for a distinction between different modules dealing with different aspects of the organization of the utterance. There is one module that takes care of the 
interpersonal organization, and another that takes care of matters of representation, much as in frameworks like Halliday's (1994) Systemic Functional Grammar and McGregor's (1997) Semiotic Grammar. Top-down orientation, on the other hand, implies that in this modular framework the interpersonal module, which takes care of speaker-hearer interaction, is primary in that it can determine choices in the representational module. In this section, I will show how both of these features are directly reflected in the behaviour of subjective modality as it has been analysed in this paper.

As explained in the previous section, the main problem with the traditional layered model was the assumption that the full set of layers is considered to be present in any type of utterance. In this perspective, association with different layers for the highest types of epistemic and deontic modality necessarily implies different status. If the highest type of deontic modality is associated with the predication, this implies that it cannot have the same subjective status as the highest type of epistemic modality, since every utterance - including those with the 'highest' type of deontic modality - always contains a propositional layer with a slot for precisely this subjective-epistemic modal operator. As argued in the previous section, I fully agree with the descriptive motivation - the divergent behaviour of tense - for associating the highest types of epistemic and deontic modality with the proposition and the predication, respectively, but I do not agree that this should lead to a different status for the two categories of modality.

In a modular system, like that of Halliday (1994), McGregor (1997) or Hengeveld (this volume), the representational association of the modal categories no longer has any influence on their interpersonal status, because representational and interpersonal functions belong to separate modules. The fact that epistemic and deontic modality have different domains (tensed versus tenseless SoAs) is a purely representational matter that can be dealt with in the representational component and does not interfere with the question of subjective status. The subjective status of epistemic and deontic modality, on the other hand, is an interpersonal issue in its own right that can be determined on the basis of function (encoding positions of commitment) and behaviour (in reaction to conditionality and interrogation) and is not related to representational questions at all. The connections that do exist between the interpersonal and representational components, finally, can be captured in the topdown orientation of the model. The representational choice between tensed and 
tenseless SoAs is steered from the interpersonal component by the choice between subjective epistemic and subjective deontic modality. Table 4 below provides a schematic representation of how the analysis of subjective modality proposed in this study can be dealt with in terms of the modular architecture proposed by Hengeveld (this volume).

\section{Table 4 about here}

In sum, we can say that the descriptive problems discussed in the first part of this paper can generally be accommodated more easily in a modular architecture with topdown orientation between interpersonal and representational components than in the traditional FG model. Because the modular approach separates the interpersonal status of an operator from possibly divergent representational associations, it also removes the most important obstacle to the inclusion of deontic modality into the subjective category: association with different layers at the representational level does not necessarily have implications for the interpersonal status of epistemic versus deontic modals. On the other hand, the top-down orientation still allows one to incorporate the link between the epistemic-deontic distinction at the interpersonal level and the tensed-tenseless distinction at the representational level, in the sense that this representational choice is steered by a choice at the interpersonal level.

There is one problem, however, which still remains unaddressed in the model proposed by Hengeveld (this volume), and that is the problem of optionality of layering at the representational level. The top-down orientation of the model can easily deal with the fact that the interpersonal choice between epistemic and deontic modality leads to a representational choice between tensed SoAs and tenseless SoAs, but this still requires a way for the representational module to deal with the fact that some structures are tensed and others are not. Assuming that the distinction between tensed and tenseless SoAs corresponds to the distinction between propositions and predications in the representational module ${ }^{x i i i}$, it is necessary to explicitly include optionality in the representational layering. Optionality of the propositional layer is a necessary prerequisite for adequate modelling of structures with subjective deontic modality.

\section{References}


Bellert, Irene (1977). On semantic and distributional properties of sentential adverbs. Linguistic Inquiry 8, 337-350.

Bolinger, Dwight (1968). The imperative in English. In To Honor Roman Jakobson, 335-362. Berlin: Mouton.

Bolinger, Dwight (1977). Is the imperative an infinitive? In Meaning and Form, Dwight Bolinger, 152-182. London: Longman.

Bolkestein, A. Machtelt (1980). Problems in the Description of Modal Verbs. Assen: Van Gorcum.

Dancygier, Barbara (1998). Conditionals and Prediction: Time, Knowledge and Causation in the Grammar of English if-then constructions. Cambridge: Cambridge University Press.

Davies, Eirian (1979). On the Semantics of Syntax. Mood and Condition in English. London: Croom Helm.

Declerck, Renaat (1991a). A Comprehensive Descriptive Grammar of English. Tokyo: Kaitakusha.

Declerck, Renaat (1991b). Tense in English. Its Structure and Use in Discourse. London: Routledge.

Declerck, Renaat \& Susan Reed (Forthcoming). Conditionals. A Data-driven Analysis. Berlin: Mouton.

Dik, Simon (1997). The Theory of Functional Grammar. Part 1: The Structure of the Clause. Ed. by Kees Hengeveld. Berlin: Mouton.

Foley, William \& Robert Van Valin (1984). Functional Syntax and Universal Grammar. Cambridge: Cambridge University Press.

Goossens, Louis (1996). English modals and functional models: a confrontation. Antwerp Papers in Linguistics 86. Antwerp: University of Antwerp.

Halliday, Michael (1970). Functional diversity in language as seen from a consideration of modality and mood in English. Foundations of Language 6, 322361.

Halliday, Michael (1975). Learning How to Mean. Explorations in the Development of Language. London: Longman.

Halliday, Michael (1994). An Introduction to Functional Grammar. London: Arnold. Hare, Richard (1970). Meaning and speech acts. Philosophical Review 79, 3-24. 
Hengeveld, Kees (1987). Clause structure and modality in Functional Grammar. In Ins and Outs of the Predication, Johan van der Auwera \& Louis Goossens (eds), 53-66. Dordrecht: Foris.

Hengeveld, Kees (1988). Illocution, mood and modality in a functional grammar of Spanish. Journal of Semantics 6, 227-269.

Hengeveld, Kees (1989). Layers and operators in Functional Grammar. Journal of Linguistics 25, 127-157.

Hengeveld, Kees (1990). The hierarchical structure of utterances. In Layers and Levels of Representation in Language Theory. A Functional View, Jan Nuyts, A. Machtelt Bolkestein \& Co Vet (eds), 1-23. Amsterdam: Benjamins.

Hengeveld, Kees (This volume). The architecture of a functional discourse grammar. In A New Architecture for Functional Discourse Grammar, J. Lachlan Machenzie \& María de los Ángeles Gómez Gonzalez (eds). Berlin: Mouton.

Hengeveld, Kees. Forthcoming. Mood and modality. In Morphology: A Handbook on Inflection and Word Formation, Geert Booij, Christian Lehmann, \& Joachim Mugdan (eds). Berlin: Mouton.

Jackendoff, Ray (1972). Semantic Interpretation in Generative Grammar. Cambridge, Mass: MIT Press.

Lyons, John (1977). Semantics. Volume 2. Cambridge: Cambridge University Press. McGregor, William (1997). Semiotic Grammar. Oxford: Oxford University Press.

Moutaouakil, Ahmed (1996). On the layering of the underlying clause structure in Functional Grammar. In Complex Structures. A Functionalist Perspective, Betty Devriendt, Louis Goossens \& Johan van der Auwera (eds), 201-227. Berlin: Mouton.

Nuyts, Jan (1992). Subjective vs. objective modality: What is the difference? In Layered Structure and Reference in a Functional Perspective, Michael Fortescue, Peter Harder \& Lars Kristoffersen (eds), 73-97. Amsterdam: Benjamins.

Nuyts, Jan (1993). Modality and the layered representation of conceptual and linguistic structure. Linguistics 31, 933-969.

Palmer, Frank (1990). Modality and the English Modals. London: Longman.

Verstraete, Jean-Christophe (2000). Attitudinal disjuncts and illocutionary force in clause combining - a response to Bill McGregor. Functions of Language 7, 117131. 
Verstraete, Jean-Christophe (Forthcoming). Subjective and objective modality: ideational and interpersonal functions in the English modal auxiliary system. To appear in Journal of Pragmatics.

${ }^{\mathrm{i}}$ I would like to thank Bert Cornillie, Kristin Davidse, Renaat Declerck, Patrick Goethals, Kees Hengeveld, Peter Lauwers, Bill McGregor, Jan Nuyts, William Van Belle, Dieter Vermandere, and an anonymous referee for more general discussions about modality and/or comments on a previous draft of this paper. A preliminary version of this paper was presented at the $9^{\text {th }}$ International Conference on Functional Grammar in Madrid. I would like to thank the members of the audience for their remarks and criticisms. Thanks also to Machtelt Bolkestein for making available a copy of Bolkestein (1980).

${ }^{i i}$ Examples taken from the Cobuild corpus are marked with $\mathrm{CB}$, and examples taken from the ICE-GB corpus are marked with their standard ICE-GB text code. The relevant modal is always underlined.

iii See Verstraete (forthcoming) for an overview of the distinction between subjective and objective modality in terms of various theories of layering.

iv As shown by Nuyts $(1992,1993)$, however, the difference between modal adjectives and adverbs cannot be explained in terms of the distinction between objective and subjective function, but must be related to three interacting parameters, viz. evidentiality, discourse functionality and performativity (Nuyts 1993).

${ }^{\mathrm{v}}$ In fact, this was the original context where this criterion was introduced, see Jackendoff (1972) and Bellert (1977).

${ }^{\mathrm{vi}}$ It is important to note that it is this commitment-suspending function of the conditional marker rather than the presence of the conditional marker as such that leads to an echo-effect. As shown in Declerck \& Reed (forthcoming), not all clauses introduced by if have the function of suspending the speaker's commitment: there are for instance what they call performative conditionals, where the if-clause contains a performatively used performative verb. Accordingly, such conditionals will not trigger any echo-effect for subjective modals, since it is only the commitment-suspending function of if that leads to echo-interpretation for subjective modals.

${ }^{\text {vii }}$ In fact, this use of deontic modality is more typically realized by periphrastic modals like have to rather than modal auxiliaries like must (Palmer 1990: 113-116, Declerck 1991a: 376-377).

${ }^{\text {viii }}$ See, however, the more descriptively oriented typology in Hengeveld (forthcoming).

${ }^{i x}$ In this respect it is not surprising that Palmer (1990: 113) lists such examples as dynamic necessity.

${ }^{x}$ That is, of course, without change of interpretation. Adding a propositional attitude marker to a subjective deontic expression is always possible, but necessarily shifts it from the subjective to the objective category. It is in fact a common rhetorical strategy to add propositional attitude markers to orders or prohibitions, in order to present the obligation as somehow existing independently from the speaker, as in Unfortunately, you cannot enter this building.

${ }^{x i}$ As I have shown in section 5.2, such configurations do occur, but crucially only in structures with nonsubjective deontic modality, which are interpersonally epistemic utterances about the existence of necessity or obligation.

xii There have been a number of proposals in the same direction within the FG tradition, for instance in Moutaouakil's (1996) argument that only declarative clauses contain a propositional layer and in Hengeveld's (1990) argument that imperative clauses lack a propositional layer. If the propositional layer is tied to the grammatical feature of tense, however, neither of these proposals is entirely adequate: epistemic interrogatives are tensed just like their declarative counterparts, and subjectivedeontic declaratives are tenseless just like their imperative counterparts.

xiii In the traditional model, the distinction between proposition and predication was motivated in terms of the interpersonal-representational distinction (Hengeveld 1989: 127-131). In Hengeveld's new proposal (this volume), what used to be the propositional layer now belongs both to the interpersonal component (as the ' $\mathrm{C}$ ' variable) and to the representational component (as the ' $\mathrm{p}$ ' variable). This implies that the proposition-predication distinction is no longer motivated by the interpersonal-representational distinction but requires a new motivation. The structural property of presence vs absence of tense is probably a good candidate for this purpose: location with respect to the temporal zero-point is a necessary prerequisite for epistemic negotiation about truth or falsity, as argued by Halliday (1994: 75). 